Journal of Materials Science: Materials in Electronics, volume 21, number 1, January 2010, pp 78-87.

\title{
Sublimation Growth of Titanium Nitride Crystals
}

\section{Li Du and J.H. Edgar}

Department of Chemical Engineering, Kansas State University, Manhattan, KS 66506, USA

Tel: 785-532-4323, Fax: 785-532-7372, Email: lidu@ksu.edu

Edward A. Kenik and Harry Meyer III

High Temperature Materials Laboratory, Oak Ridge National Laboratory, Oak Ridge, TN 37831

\begin{abstract}
The sublimation-recondensation growth of titanium nitride crystals with N/Ti ratio of 0.99 on tungsten substrates is reported. The growth rate dependence on temperature and pressure was determined, and the calculated activation energy was $775.8 \pm 29.8 \mathrm{~kJ} / \mathrm{mol}$. The lateral and vertical growth rates changed with the time of growth and the fraction of the tungsten substrate surface covered. The orientation relationship of TiN (001) \| W (001) with TiN [100] || W [110], a $45^{\circ}$ angle between TiN [100] and $\mathrm{W}$ [100], occurs not only for TiN crystals deposited on (001) textured tungsten but also for TiN crystals deposited on randomly orientated tungsten. This study demonstrates that this preferred orientational relationship minimizes the lattice mismatch between the TiN and tungsten.
\end{abstract}

Keywords: TiN, sublimation growth, tungsten substrate, activation energy, orientation 
Journal of Materials Science: Materials in Electronics, volume 21, number 1, January 2010, pp 78-87.

\section{Introduction}

Refractory transition metal nitrides such as $\mathrm{ScN}$ and $\mathrm{TiN}$, are attractive candidates for combining as layered structures or alloys with gallium nitride and related group III nitride semiconductors, because they can have similar lattice constants, share a common element and exhibit dual properties characteristics of both covalent compounds and metals [1]. Usui et al [2] studied the role of a TiN layer in GaN epitaxial growth and crystal quality in a void-assisted separation method. The small GaN islands that formed on the TiN nano-net in the beginning of epitaxy have crystal facets that introduce dislocation bending and reduce the threading dislocation density in the $\mathrm{GaN}$ layer. Thus, the TiN layer separates the GaN layer from the substrate and improves the crystal quality. Chen et al [3] employed $\mathrm{TiN}$ as a reflective layer between the GaN device layer and its silicon substrate. This improved the efficiency of GaN light emitting diodes compared to those grown directly on silicon. More recently, Oliver et al [4] used a composite $\mathrm{ZrN} / \mathrm{AlN}$ layer on silicon for similar purposes. The $\mathrm{ZrN}$ reduced the light lost by reflecting it away from the substrate and facilitated electrical contact formation. Moram et al [5] investigated nitride layers of zirconium, hafnium, niobium, chromium, and scandium on silicon to block the threading of dislocations in the epitaxial gallium nitride. Scandium nitride layers were the most effective at reducing the $\mathrm{GaN}$ dislocation density to a minimum value of $3 \mathrm{x}$ $107 \mathrm{~cm}-2$. Bulk ScN crystals have also been proposed as a substrate for gallium nitride, due to its small lattice constant mismatch, $-0.1 \%$ [6]. Furthermore, epitaxial growth of TiN was investigated on $\mathrm{Si}$ and GaAs substrate [7]. Both orientation relationships of TiN [001] || GaAs [110] and TiN [1 $1 \overline{1} 0] \|$ GaAs [ $\overline{1} 10]$ have been found for TiN growth on GaAs (001).

In addition, titanium nitride is a major industrial material because of its excellent properties, including abrasive wear resistance, good lubricating characteristics and low diffusivity. This latter characteristic makes it a good diffusion barrier between Si and Al, Si and $\mathrm{Ag}$, and $\mathrm{Ti}$ and $\mathrm{Pt}$ [8]. Titanium nitride belongs to the $\mathrm{Fm} 3 \mathrm{~m}$ space group and has a rock salt structure (lattice constant $4.240 \AA$ ), which is an FCC crystal structure with all octahedral interstitial positions occupied. $\mathrm{TiN}_{\mathrm{x}}$ is stable in the composition range of $\mathrm{TiN}_{0.6}$ to $\mathrm{TiN}_{1.1}$, with nitrogen atom vacancy concentrations up to 50 atomic \% [8] The high melting point $\left(2930^{\circ} \mathrm{C}\right)$ [9], extreme hardness $\left(2000 \mathrm{~kg} / \mathrm{mm}^{2}\right)$ [10], good resistance to wear and corrosion, as well as the high phase stability (thermodynamic, metallurgical and chemical), of TiN results from the covalent nature of the Ti-N bonds, and its rock salt crystal structure [11], while its relatively low thermal conductivity $\left(19.2 \mathrm{~W} / \mathrm{m} \cdot{ }^{\circ} \mathrm{C}\right)[8]$, compared to $\mathrm{Cu}\left(401 \mathrm{~W} / \mathrm{m} \cdot{ }^{\circ} \mathrm{C}\right)[12], \mathrm{AlN}\left(285 \mathrm{~W} / \mathrm{m} \cdot{ }^{\circ} \mathrm{C}\right)$ or $\mathrm{GaN}$ $\left(130 \mathrm{~W} / \mathrm{m} \cdot{ }^{\circ} \mathrm{C}\right)$ [13], and low electrical resistivity $(20 \pm 10 \mu \Omega \cdot \mathrm{cm})$ [8] are from its metallic characteristics.

Although physical vapor deposition methods are typically employed to prepare TiN thin films to ensure a low thermal budget [14], many other methods have also been used including chemical vapor deposition with $\mathrm{TiCl}_{4}$ and $\mathrm{NH}_{3}$ [15] or $\mathrm{TiCl}_{4}-\mathrm{N}_{2}-\mathrm{H}_{2}$ mixtures [16], reactive sputtering Ti metal in an $\mathrm{Ar} / \mathrm{N}_{2}$ gas mixture [17], evaporation and laser physical vapor deposition. To produce bulk crystals, sublimation growth, one of the physical vapor transport growth methods, is an attractive approach, as it has higher growth rates, morphological stability and is an easily implemented process, and produces crystals with lower defect density compared with CVD growth. Sublimation growth has been most successfully employed to grow SiC [18] and AlN [19] bulk single crystals.

In our previous study [20], we investigated the morphology and crystallographic orientation of TiN crystals grown by sublimation at temperatures of $1820^{\circ} \mathrm{C} \sim 1920^{\circ} \mathrm{C}$, and 
Journal of Materials Science: Materials in Electronics, volume 21, number 1, January 2010, pp 78-87.

pressures of $0.2 \mathrm{~atm} \sim 1.2 \mathrm{~atm}$. The TiN crystals deposited on $\mathrm{W}(001)$ exhibited a preferred orientation of $\mathrm{TiN}(001) \| \mathrm{W}(001)$ and $\mathrm{TiN}$ [100] $\| \mathrm{W}$ [110], which resulted in a $45^{\circ}$ angle between $\mathrm{TiN}$ [100] and $\mathrm{W}$ [100]. Therefore, the orientation of TiN crystal growth is easily controlled since $\mathrm{W}$ [100] is a common orientation of rolled tungsten sheet, providing an additional advantage for TiN crystal growth compare to other materials grown by sublimation.

In this study, the sublimation growth of titanium nitride crystals on tungsten substrates is reported in more detail. The TiN crystals orientation is further studied not only on (001) textured tungsten substrates, but also on non-(001) orientated (random) tungsten substrates. The dependence of the growth rate on temperature and pressure was established and compared with AlN sublimation growth under similar conditions. The activation energy was also calculated based on the change in the TiN growth rate with temperature. The elemental composition and the $\mathrm{N} / \mathrm{Ti}$ ratio before and after crystal growth of the source materials were measured to see if there were any significant variations in the TiN composition with growth conditions. The morphology of the TiN crystals during different stages of growth was studied to determine how their characteristics changed with time. The overall growth rate was divided into two parts, the vertical rate (perpendicular to the surface) and lateral rate (parallel to the surface), and their relationship with the overall growth rate, dependence on the length of growth, and function on crystal morphology were investigated and discussed.

\section{Experimental}

The TiN crystals were grown in a resistively-heated tungsten furnace using a tungsten crucible within a tungsten retort to contain the titanium vapor. TiN crystals were deposited on a tungsten foil ( $25 \mathrm{~mm}$ diameter) placed on the top of the crucible. The source, TiN powder with oxygen as the main impurity, was sintered before crystal growth, to reduce the oxygen concentration. The TiN powder source was sintered by first baking in a 5\% hydrogen and $95 \%$ argon gas mixture at $1000^{\circ} \mathrm{C}$ for about 2 hours, then heating in ultra pure nitrogen gas to $1900^{\circ} \mathrm{C}$ for another 4 hours. Chemical analysis was performed of some of the nonmetallic elements $(\mathrm{C}, \mathrm{N}$, and $\mathrm{O}$ ) in the TiN source to determine how their concentrations were changed by sintering. The elements' concentrations in the TiN source before and after this process were measured by the gas fusion method. Before each growth, the source was again baked in 5\% hydrogen and $95 \%$ argon gas mixture at $1000{ }^{\circ} \mathrm{C}$ for about 1 hour to reduce the surface oxide. The growth temperature was measured by an optical pyrometer focused on the top of the retort, and a temperature difference of approximately $50^{\circ} \mathrm{C}$ was maintained between the source zone and the crystal growth zone. All the experiments were performed in pure nitrogen, and the growth time was varied from 30 minutes to 15 hours. The growth rate was investigated as a function of a number of temperature $\left(1980-2110^{\circ} \mathrm{C}\right)$ and pressure $(0.06-1.25 \mathrm{~atm})$ combinations

The overall growth rate, defined as mass change per unit time, was determined by dividing the TiN crystal weight increase by the time at the growth conditions. The film thickness of each sample was estimated by $h=m /(S \rho)$, knowing the total weight increase- $m$, density- $\rho$, and the area- $S$ of the deposited material. The grain sizes (the projected area of individual crystals) and the grain heights were measured using scanning electron microscopy (SEM - FEI Philips XL-30, Eindhoven, The Netherlands) and averaged from a number of condensed TiN crystals at each growth condition. The average crystal dimensions were determined by measuring twenty four crystals selected at random from different regions of each sample, then eliminating the two largest and smallest crystals from the calculation, and averaging the remaining twenty. 
Journal of Materials Science: Materials in Electronics, volume 21, number 1, January 2010, pp 78-87.

The orientation of the TiN crystals and the underlying tungsten substrate were determined independently by both X-ray diffraction (XRD) and electron backscatter diffraction (EBSD) in a SEM. Pole figures from individual TiN crystals and their underlying tungsten substrate grains were collected by EBSD to determine their relative orientation relationships. Families of (001) planes were used to reveal the orientation relationship between the TiN and $\mathrm{W}$ lattices. The elemental composition for TiN powders and crystals were measured by Auger electron spectroscopy. Auger analysis was done using a Phi-680 scanning Auger nanoprobe (Physical Electronics, Inc. Chanhassen, MN) with a field emission electron gun, cylindrical mirror electron energy analyzer, and Ar-ion sputter gun. The energy and current of the probe electron beam was $20 \mathrm{kV}$ and $10 \mathrm{nA}$, respectively and give a spot size for the probe beam of $\sim 15 \mathrm{~nm}$. The beam was held at fixed points to yield spectral information (i.e. surface composition) for that feature or was rastered over a given area to give either secondary electron images or Auger elemental maps. Depth profiling was performed in selected areas by monitoring the Auger signal of selected elements while alternately sputtering for a given amount of time. The sputter rate that was used (calibrated for a standard $\mathrm{SiO}_{2}$ film) was $150 \mathrm{~nm} / \mathrm{min}$. The base pressure of the analysis chamber was $\sim 5 \times 10^{-10}$ torr and was maintained by introducing samples through a turbo-pumped load-lock. Data was acquired and analyzed using Phi PC-Access and Phi Matlab software, respectively.

\section{Results and Discussion}

Though several solid and vapor phase species that may form in the Ti-N system according to the available thermal data in JANAF table[9], the most probable gas phase products of TiN decomposition are those species with the lowest Gibbs free energy of formation: $\operatorname{Ti}(\mathrm{g})$ and $\mathrm{N}_{2}(\mathrm{~g})$. Thus the crystal growth process begins with source decomposition and the reaction:

$$
2 \operatorname{TiN}(s) \leftrightarrow 2 \mathrm{Ti}(\mathrm{g})+\mathrm{N}_{2}(\mathrm{~g})
$$

which has a Gibbs free energy of $273.96 \mathrm{~kJ} / \mathrm{mol}$ at $2300 \mathrm{~K}\left(2027{ }^{\circ} \mathrm{C}\right)$ and $251.96 \mathrm{~kJ} / \mathrm{mol}$ at 2400 $\left.\mathrm{K}\left(2127^{\circ} \mathrm{C}\right)[9]\right)$. Because the reverse reaction has a large negative Gibbs free energy change, the crystals readily condense in the cooler region of the furnace.

It is useful to compare the sublimation of $\mathrm{TiN}$ to another material, aluminum nitride, since sublimation growth has been successfully employed to produce AlN with decomposition and the reaction:

$$
2 A l N(s) \leftrightarrow 2 A l(g)+N_{2}(g)
$$

Titanium nitride has a higher melting point $\left(2930^{\circ} \mathrm{C}\right)[19]$ than aluminum nitride (m.p. $=2200^{\circ} \mathrm{C}$ and b.p. $=2517^{\circ} \mathrm{C}[21]$ ). Although the standard formation enthalpy of titanium nitride and aluminum nitride are similar ( TiN, $-337.649 \mathrm{~kJ} / \mathrm{mol}$; $\mathrm{AlN},-317.98 \mathrm{~kJ} / \mathrm{mol}$ at $298.15^{\circ} \mathrm{C}$ ), the standard formation enthalpy of titanium gas is about $100 \mathrm{~kJ} / \mathrm{mol}$ larger than that of aluminum gas at the temperature below their boiling point. Hence, titanium's vapor pressure over TiN (for stoichiometric decomposition) is significantly lower than aluminum's vapor pressure over AlN under the same conditions. For pure material sublimation under the ideal case of equations (1) and (2), assuming a constant inert gas pressure of $0.1 \mathrm{MPa}$, the calculated Ti vapor pressure over TiN ranges from 2.6 $\mathrm{Pa}$ at $1927{ }^{\circ} \mathrm{C}$ to $78.8 \mathrm{~Pa}$ at $2227{ }^{\circ} \mathrm{C}$ [9], while the calculated $\mathrm{Al}$ vapor pressure over AlN ranges from $980 \mathrm{~Pa}$ to $15,000 \mathrm{~Pa}$ [9] at the same conditions. With nitrogen as the ambient gas, which is typical in sublimation growth of metal nitrides, both the Ti vapor pressure over TiN and $\mathrm{Al}$ vapor pressure over $\mathrm{AlN}$ are lower than the calculated values, since the 
Journal of Materials Science: Materials in Electronics, volume 21, number 1, January 2010, pp 78-87.

extra nitrogen will drive reactions (1) and (2) to the left side. In short, because of the much lower vapor pressure of $\mathrm{Ti}$, its growth rate will be much lower than that of AlN for the same conditions, which was also confirmed by the experiment results.

\section{Composition and morphology}

The measured weight percents of nitrogen, oxygen, and carbon in the original TiN powder were $22.0 \%, 0.51 \%$, and $0.049 \%$, respectively. After using the same TiN source for several crystal growth experiments, the concentration of these elements were $22.0 \%, 0.32 \%$, and $0.26 \%$, respectively. Thus, the oxygen concentration was reduced while the carbon concentration was increased. Assuming the impurities formed compounds with stoichiometries of $\mathrm{TiC}$ and $\mathrm{TiO}_{2}$, then the $\mathrm{N} / \mathrm{Ti}$ ratio in the original powder is similar to that found in the remaining source, $\mathrm{TiN}_{0.984}$ and $\mathrm{TiN}_{0.989}$, respectively. For the crystals, Auger analysis showed that the N/Ti ratio was the same regardless of the temperature and pressure under which they were grown. Auger analysis also confirmed that the oxygen concentration in the crystals was lower than in the original powder and the N/Ti atomic ratio in the crystal was similar to the powder.

The TiN crystals were a bright golden color and most of the large single grains have an orthorhombic shape, as shown in Figure 1. Figure 2 shows SEM images (parallel to the growth direction) for TiN crystals grown for 30 mins at $2100{ }^{\circ} \mathrm{C}, 1.25 \mathrm{~atm}(\mathrm{a}), 2000{ }^{\circ} \mathrm{C}, 0.8 \mathrm{~atm}$ (b), and 15 hours at $2000{ }^{\circ} \mathrm{C}, 0.2 \mathrm{~atm}(\mathrm{c}, \mathrm{d})$. The crystals that formed within 30 minutes were square, rectangular, or triangular in morphology/shape. The crystals tended to nucleate along the grain boundaries of the tungsten substrate (Fig. 2a). Within the same tungsten grain, many of the individual TiN crystals had similar shapes and were oriented in the same direction (Fig. 2b). These TiN crystals continued to grow with the same orientation as it nucleated. After several hours of growth, some single grains still maintained square or rectangular surfaces (Fig. 2c), but the majority of grains merged together to display less regular shapes (Fig. 2d). The side view (perpendicular to the growth direction) SEM images of TiN crystals provide more details about their morphology, as shown in Figure 3 and Figure 4. The lateral dimensions of the crystals are generally larger than their vertical dimension for samples grown for short times, less than 30 minutes. The TiN crystal grains are thin, flat tablet-shaped. Those crystals with square or rectangular top areas exhibited different shapes, either thin orthorhombic (Fig. 3a) or wedge (Fig. 3b), while those with triangular surfaces exhibited shapes of either truncated cubes (Fig. 3c) or titled wedges (Fig. 3d). For growth times of 12 hours and longer, though most crystals retain an orthorhombic shape (Fig. 4a), the majority of the TiN crystals form a continuous film (Fig. 4b) that were separated from the tungsten substrate in some regions. This separation initiates at voids formed between merged TiN grains and expands by the thermal expansion coefficient mismatch between $\mathrm{TiN}$ and tungsten during cooling from the growth temperature. Furthermore, for samples grown for 30 mins, the majority of the crystals had similar size and shape within the same sample, which suggested that most crystals nucleated at roughly same time. For samples grown more than 12 hours, the majority of crystals that merged together had a smaller size than individual crystals, which suggests that lateral growth was limited by proximity to neighboring crystals.

\section{Orientation}

EBSD analysis on the tungsten substrate and condensed TiN crystals revealed the orientational relationship TiN (001) \| W (001) with normal direction TiN [100] \| W [110], a 45 rotation between the TiN and $\mathrm{W}$ lattices, as defined by their primary unit cell directions [100]. If 
Journal of Materials Science: Materials in Electronics, volume 21, number 1, January 2010, pp 78-87.

the tungsten substrate (001) plane was parallel to the growth surface, the TiN crystal (001) planes were also parallel to the surface, producing an orthorhombic crystal shape. If the tungsten substrate (001) plane was slightly offset (tilted) from the surface, the TiN crystal (001) planes were also slightly offset from the surface, but were still parallel with the underling W (001) plane with normal direction TiN [100] $\| \mathrm{W}$ [110], producing either a truncated cube or tilted wedge crystal shape. Figure 5a and 5b are the EBSD results for a group of TiN crystals grown on the tungsten substrate that were aligned in two linear arrays near the grain boundaries. The 12 randomly selected TiN grains were all oriented with a TiN [001] plane normal at the center of the pole figure (perpendicular to the substrate) and their other [010] and [100] plane normals lying in the plane of the substrate (Fig. 5a). Five different points (1, 5, 6, 7 and 8) for the underling tungsten grain and 3 different points (2, 3 and 4) for nearby tungsten grains (corresponding to the solid and hollow symbols, respectively) were selected for EBSD analysis (Fig. 5b). The tungsten grain underlying the selected TiN crystals clearly is oriented with W [001] perpendicular to the substrate and that there is a $45^{\circ}$ angle between TiN [100] and $\mathrm{W}$ [100] (see respective pole figures in Fig. 5a, b). The three adjacent tungsten grains exhibit significantly different orientations from the center grain. Fig. 5c and 5d are the EBSD results for TiN crystals grown on three adjacent tungsten grains having different orientations, i.e., both the W (001) plane for these three different tungsten grains and the TiN (001) plane for the TiN crystals grown on these grains are tilted with respect to the surface normal. Nevertheless, their (001) planes are parallel, with a $45^{\circ}$ angle between the perpendicular TiN [100] and $\mathrm{W}$ [100] directions. For example, the TiN crystals labeled 3 and 4 in Fig. 5c are grown on the tungsten grain at point 3 in Fig. 5d, and the normal TiN [001] lies at the same position with normal $\mathrm{W}$ [001]; though there is $180^{\circ}$ angle between two crystals' TiN [010] normals, they still have same orientation as the $<100>$ of rock salt crystal structure is a $\mathrm{C}_{4}$ rotation axis; obviously there is a $45^{\circ}$ angle between TiN [100] and W [100]. Similar orientations are seen between the TiN crystals at points 1 and 2 in Fig. 5c and tungsten grain at point 1 in Fig. 5d; between TiN crystals at points 5 and 6 in Fig. $5 \mathrm{c}$ and tungsten grain at point 2 in Fig. $5 \mathrm{~d}$. This orientation relationship was confirmed by XRD for samples grown for more than 12 hours. The XRD analysis of the original polycrystalline tungsten foil substrate along the growth direction displayed a highly oriented (200) texture. Small (111), (220), and (311) diffraction peaks were also observed, but had negligible intensity relative to the (200) diffraction peak. The XRD pattern from a $6 \mathrm{~mm}$ TiN crystal sample grown on the highly-oriented W (200) foil also displayed highly oriented (200) texture (Fig. 6).

This orientation preference between TiN crystals and tungsten substrates minimizes the lattice constant mismatch. Since the lattice constant of TiN (4.240 $\AA$ ) is much larger than tungsten $(3.165 \AA)$, their cube-on-cube lattice mismatch is quite large, $33.96 \%$ (based on tungsten). However, rotating the unit cell by $45^{\circ}$ and considering the square that is formed by the nearest 4 titanium atoms or nitrogen atoms as a unit (Figure 7), the nearest atom distance in this new square is $2.998 \AA$ which give a cube-on-cube atom distance mismatch of $5.28 \%$ (based on tungsten). Thus, the TiN crystals orient on tungsten to minimize the lattice mismatch. Therefore a $45^{\circ}$ angle exist between the tungsten unit cell and TiN unit cell, and result in orientational relationship TiN (001) || W (001) with normal direction TiN [100] || W [110]. Even if the surface $\mathrm{W}\{001\}$ planes are slightly tilted off-axis, the above orientational relationship is still followed as it offers the minimum lattice mismatch, with $\mathrm{TiN}(001)$ parallel to $\mathrm{W}(001)$, slightly offset from the growth surface. 
Journal of Materials Science: Materials in Electronics, volume 21, number 1, January 2010, pp 78-87.

\section{Overall growth rate}

The sublimation growth rate for TiN crystals on $\mathrm{W}$ is much lower than that for AlN under similar growth conditions. For instance, the AlN sublimation growth rate is 1950 $\mathrm{mg} / \mathrm{hr}$ (unpublished work by $\mathrm{Li} \mathrm{Du}$ and J.H.Edgar) while the TiN crystal growth rate is only 6 $\mathrm{mg} / \mathrm{hr}$ at $2100{ }^{\circ} \mathrm{C}, 0.8 \mathrm{~atm}$ (measured in this study). Increasing the temperature or decreasing the pressure enhances the TiN growth rate; the highest growth rate in this study was $98.89 \mathrm{mg} / \mathrm{hr}$ at $2100{ }^{\circ} \mathrm{C}$ and $0.06 \mathrm{~atm}$. Figures 8 and 9 show the dependence of the growth rate on temperature and pressure: the logarithmic growth rate is first order dependent on reciprocal temperature, while growth rate itself varies with reciprocal pressure to the 1.5 power.

By combining the Arrhenius equation with sublimation-recondensation kinetics, a general expression can be obtained to determine the activation energy of TiN sublimation growth:

$$
\left.\begin{array}{l}
r=d \alpha / d t=k f(\alpha) \\
\ln r=\left(-\frac{E a}{R T}\right)+\ln A
\end{array}\right\} \Rightarrow \ln \frac{d \alpha}{d t}=\left(-\frac{E a}{R T}\right)+\ln A+\ln f[\alpha]
$$

where $E a$ is the activation energy, $A$ is the pre-exponential factor or frequency factor, $R$ is the ideal gas constant, $r$ is the growth rate, $\alpha$ is the degree of conversion, and $f(\alpha)$ is a mathematical function whose form depends on the reaction type. For the Ti+N system, the relationship between the rate constant $k$ and the growth rate above- $(d \alpha / d t)=k f(\alpha)-$ has not yet been determined. However, as the transport of growth species from source to growing surface is often the rate limiting step in vapor crystal growth [22], equilibrium can be assumed at the surfaces of the source and seed. So for reaction (1):

$$
K^{e q}=\frac{[T i]^{2}\left[N_{2}\right]}{[T i N]^{2}}=\frac{\left(f_{T i}^{e q}\right)^{2}\left(f_{N_{2}}^{e q}\right)}{\left(a_{T i N}{ }^{e q}\right)^{2}}
$$

Since the growth pressures used in this study were not high $(<1.25 \mathrm{~atm})$, solid species activity is close to unity and gas fugacity can be represent by gas species partial pressure, that is:

$$
K^{e q}=\left(P_{T i}^{e q}\right)^{2}\left(P_{N_{2}}^{e q}\right)
$$

For a fixed growth temperature and pressure, the local gas phase species concentration at the growth surface remains the same and $f(\alpha)$ is approximately constant. Therefore, the sublimation growth rate is proportional to the rate constant and yields a first order dependence of logarithmic growth rate on reciprocal temperature at same pressure (confirmed in Fig. 8):

$$
\frac{d \ln r}{d T}=\frac{E a}{R T^{2}}\left(r=\frac{d \alpha}{d t}\right)
$$

The calculated activation energy is $775.8 \pm 29.8 \mathrm{~kJ} / \mathrm{mol}$ (from Fig. 8), which is very close to enthalpy of TiN sublimation from available thermodynamic data [9] with $781.6 \mathrm{~kJ} / \mathrm{mol}$ at $2300 \mathrm{~K}$ $\left(2027^{\circ} \mathrm{C}\right)$ and $779.7 \mathrm{~kJ} / \mathrm{mol}$ at $2400 \mathrm{~K}\left(2127^{\circ} \mathrm{C}\right)$ in the growth temperature range.

\section{Lateral and vertical growth rates}

The average size and height of the condensed TiN crystals changed with growth temperature, pressure and time. Generally, at the same temperature and pressure, longer growth time resulted in larger crystals, and after the same growth time, crystals were larger at a higher temperature or a lower pressure because of a higher growth rate. For example, after 30 mins growth at $1.25 \mathrm{~atm}$, when the temperature was increased from $2000{ }^{\circ} \mathrm{C}$ to $2100{ }^{\circ} \mathrm{C}$, the average size of the crystals increased from about $110 \mu \mathrm{m}^{2}$ to $594 \mu \mathrm{m}^{2}$ (a factor of 5.4), while after 30 mins growth at $0.8 \mathrm{~atm}$, when the temperature was increased from $2000{ }^{\circ} \mathrm{C}$ to $2100{ }^{\circ} \mathrm{C}$, the 
Journal of Materials Science: Materials in Electronics, volume 21, number 1, January 2010, pp 78-87.

average size of the crystal increased from about $215 \mu \mathrm{m}^{2}$ to $1150 \mu \mathrm{m}^{2}$ (a factor of 5.4). For crystals grown over several hours, with varied temperature and pressure, the average size change was not as clear as the size changes observed after 30 mins growth, since most TiN crystals merged together after longer times. Two examples are two sets of experiments for size change after 15 hours growth at 0.2 atm and 12 hour growth at 0.06 atm (see Fig. 2 and Fig. 4). When the temperature was increased from $2000{ }^{\circ} \mathrm{C}$ to $2100{ }^{\circ} \mathrm{C}$, the average size of the TiN crystals grown at $0.2 \mathrm{~atm}$ increased from about $1.75 \times 10^{4} \mu \mathrm{m}^{2}$ to $5.83 \times 10^{4} \mu \mathrm{m}^{2}$ (a factor of 3.3), while the average size of the crystals grown at $0.06 \mathrm{~atm}$ increased from about $5.06 \times 10^{4} \mu \mathrm{m}^{2}$ to 1.37 $\mathrm{x} 10^{5} \mathrm{~mm}^{2}$ (a factor of 2.7); these two factors are smaller than the size change factors for samples grown in 30 mins. However, the average TiN crystal heights changed with the growth temperature; when the temperature was increased from $2000{ }^{\circ} \mathrm{C}$ to $2100{ }^{\circ} \mathrm{C}$, the average height increased from about $77 \mu \mathrm{m}$ to $392 \mu \mathrm{m}$ (a factor of 5.1) for crystals grown at $0.2 \mathrm{~atm}$ (see Fig. 4) and from about $169 \mu \mathrm{m}$ to $954 \mu \mathrm{m}$ (a factor of 5.7) for crystals grown 0.06 atm.

Although the overall growth rate depends on temperature and pressure in general, the lateral and vertical growth rates also changed with time. The lateral growth rate is much higher initially (30 mins for example) for individual crystals and decreases after many of the grains have merged together. The vertical growth rate follows an opposite trend. To investigate the lateral and vertical growth rates of the TiN crystals, we define the lateral rate as the projected area (or size) change of the crystal per time with units of $\mu \mathrm{m}^{2} / \mathrm{hr}$, and vertical rate as thickness (or height) change of the crystal per time with the unit of $\mu \mathrm{m} / \mathrm{hr}$. Since the lateral rate has different units $\left(\mu \mathrm{m}^{2} / \mathrm{h}\right)$ than the vertical rate, $(\mu \mathrm{m} / \mathrm{hr})$, a basic arithmetic comparison may not be effective, hence we will compare each with the overall growth rate at different growth stages. As the crystal structure of TiN is rock salt, if we consider the volume of each grain to be equal (prism) or proportional (pyramid) to the product of the grain size (s) and grain height (h), and the majority of the crystals nucleated at same time (changes in crystal quantity can be neglected), the growth rate $r$ yields:

$$
r=n \rho C \frac{d V}{d t}=n \rho C\left(s \frac{d h}{d t}+h \frac{d s}{d t}\right)
$$

where $C$ is a constant, $\rho$ is density, $n$ is the crystal quantity and $\mathrm{V}$ is average volume of a crystal.

At the initial growth stage, the majority of TiN crystals form as individual crystals, therefore competitive growth between neighboring crystals can be neglected. Thus, the logarithmic value for one of the two variables on the right side of equation (7), $s$ and $h$, shows first-order dependence on reciprocal temperature only if the other is constant or nearly constant. This leads to the following deduction:

$$
\left.\begin{array}{l}
\frac{d \ln r}{d T}=d \ln \left(s \frac{d h}{d t}+h \frac{d s}{d t}\right) / d T=\frac{E a}{R T^{2}} \\
\text { lateral rate } l=\frac{d s}{d t}, \text { vertical rate } v=\frac{d h}{d t}
\end{array}\right\} \Rightarrow \begin{cases}\frac{d \ln v}{d T}=\frac{E a}{R T^{2}} ; & \text { s is constant } \\
\frac{d \ln l}{d T}=\frac{E a}{R T^{2}} ; & \mathrm{h} \text { is constant }\end{cases}
$$

Two sets of experiments were conducted, for $30 \mathrm{~min}$ growth times to guarantee that a majority of crystals are present as individual crystals, to investigate the lateral and vertical growth rates at the initial growth stage; (1) $0.8 \mathrm{~atm}$ with temperature range from $2000{ }^{\circ} \mathrm{C}$ to $2100{ }^{\circ} \mathrm{C}$ and (2) 1.25 atm with temperature range from $2000{ }^{\circ} \mathrm{C}$ to $2100{ }^{\circ} \mathrm{C}$. The logarithmic lateral growth rates versus reciprocal temperature for each are plotted in Figure 10. Each shows a first order dependence on the reciprocal temperature. The products of the two slopes and the general gas constant give activation energies of about 752.0 and 757.3, which are in the range of the 
Journal of Materials Science: Materials in Electronics, volume 21, number 1, January 2010, pp 78-87.

calculated activation energy $775.8 \pm 29.8 \mathrm{~kJ} / \mathrm{mol}$. This implies that the lateral growth rate for each experiment is proportional to the overall growth rate, and their vertical rates can be neglected.

After the TiN crystals merge together, the TiN crystals grew vertically as the height increased and laterally by competitive growth with neighboring crystals. Fast-growing crystals will increase in lateral size as slow-growing grains will be blocked and eventually disappear from top view. Two sets of experiments with growth time longer than 12 hours were conducted to compare lateral and vertical growth rates after many TiN crystals had merged together; (1) 12 hours growth at 0.06 atm with temperature range from $2000{ }^{\circ} \mathrm{C}$ to $2100{ }^{\circ} \mathrm{C}$ and (2) 15 hours growth at $0.2 \mathrm{~atm}$ with temperature range from $1980{ }^{\circ} \mathrm{C}$ to $2110{ }^{\circ} \mathrm{C}$. The logarithmic vertical growth rates show a first order dependence on the reciprocal temperature and are also plotted in Figure 10. The products of the four slopes and the gas constant give values that are all in the range of the calculated activation energy $775.8 \pm 29.8 \mathrm{~kJ} / \mathrm{mol}$ ( 777.5 and 746.9 , respectively), indicating the vertical growth rates for these two sets of experiments are proportional to their overall growth rates and are significantly higher than those observed at the initial stage of growth. Regarding the lateral growth rates for these two experiments, both the crystal morphology (SEM images) and size statistics described previously showed that they are limited by interaction between the neighboring crystals and lower than at the initial stage.

These results show that lateral growth predominates initially, while vertical growth becomes more important after the crystals have merged together and the surface of the tungsten becomes covered with TiN. Growth is more likely to be 2D growth initially. The length of the initial stage may vary depending on the growth temperature and pressure. In this study, growth for 30 mins was within the initial growth stage at 1.25 atm and 0.8 atm between $2000^{\circ} \mathrm{C}$ to $2100^{\circ} \mathrm{C}$. As a result of the much higher overall growth rate, the initial growth stage at 0.2 atm and $0.06 \mathrm{~atm}$ between $2000{ }^{\circ} \mathrm{C}$ to $2100{ }^{\circ} \mathrm{C}$ (TiN grains merged together much quicker) are much less than 30 mins and negligible compare to 12 hours, so that the 'zero' vertical rate in this stage does not affect the overall vertical rate in the calculation.

\section{Conclusions}

The sublimation-recondensation technique is a viable method to produce TiN bulk crystals on tungsten substrates. The stoichiometry of the crystals (N/Ti ratio) is 0.99 . Lateral growth predominates initially and vertical growth becomes more important after TiN crystals merge together. The crystal growth rate increases exponentially with temperature, inversely with the total pressure to the 1.5 power, and the calculated activation energy is $775.8 \pm 29.8 \mathrm{~kJ} / \mathrm{mol}$. The XRD and EBSD analysis revealed that the TiN crystals and underlying tungsten substrate grains have an orientation relationship of TiN (001) $\| \mathrm{W}(001)$ with TiN [100] \| W [110], which leads a $45^{\circ}$ angle between the TiN and $\mathrm{W}$ lattice. For tungsten substrate grains with $\mathrm{W}(001)$ planes offset from the surface, the TiN (001) planes are still parallel to $\mathrm{W}(001)$ planes to minimize the lattice mismatch.

\section{ACKNOWLEDGEMENTS}

The support of the NSF through the grants DMR 0408874 is greatly appreciated. EBSD analysis was conducted at the Oak Ridge National Laboratory SHaRE User Facility, which is sponsored by the Division of Scientific User Facilities, Office of Science, U.S. Department of Energy. Auger Electron Spectroscopy was sponsored by the Assistant Secretary for Energy Efficiency and Renewable Energy, Office of FreedomCAR and Vehicle Technologies, as part of 
Journal of Materials Science: Materials in Electronics, volume 21, number 1, January 2010, pp 78-87.

the Oak Ridge National Laboratory High Temperature Materials Laboratory User Program, managed by UT-Battelle, LLC, for the U.S. Department of Energy under contract number DEAC05-00OR22725. 
Journal of Materials Science: Materials in Electronics, volume 21, number 1, January 2010, pp 78-87.

\section{Reference}

1. L.E. Toth, Transition Metal Carbides and Nitrides, (Academic Press, New York,1971), p.156.

2. A.Usui, T. Ichihashi, K.Kobayashi, H, Sunakawa, Y. Oshima, T. Eri, and M. Shibata, Phys. Stat. sol. (a) 194, No.2, (2002) pp. 572-575

3. N.C. Chen, W.C. Lien, C.F. Shih, P.H. Chang, T.W. Wang, and M.C. Wu, Appl. Phys. Lett. 88191110 (2006)

4. M.H. Oliver, J.L. Schroeder, D.A. Ewoldt, I.H. Wildeson, V. Rawat, R. Colby, P.R. Cantwell, E.A. Stach, and T.D. Sands, Appl. Phys. Lett. 93023109 (2008).

5. M.A. Moram, M.J. Kappers, Y. Zhang, Z.H. Barber, and C.J. Humphreys, Phys. Stat. Sol. A 205 (2008), p.1064.

6. Z. Gu, J.H. Edgar, J. Pomeroy, M. Kuball, and D.W. Coffey, J. Mater. Sci.: Mater. Electron., 15 (2004), p.555.

7. T. Zheleva, K. Jagannadham, and J. Narayan, J. Appl. Phys. 75(1994), p. 860.

8. Pierson, H.O. Handbook of Refractory Carbides and Nitrides, (William Andrew Publishing/Noyes, 1996), p.193.

9. M.W. Chase, Jr., 4th ed. American Chemical Society and American Institute of Physics, Washington D.C., (1998).

10. Il-seok Kim and Prashant N.Kumta, J. Mater. Chem. 13(2003), pp.2028-2035

11. P. Patsalas and S. Logothetidis, J. Appl. Phys. 90 (2001), p.4725.

12. Wikipedia, http://en.wikipedia.org/wiki/Copper

13. James H. Edgar, Properties of Group III Nitrides, (The Institution of Electrical Enginners, London UK 1994), p.26-32

14. K. Wasa, S. Hayakawa, Handbook of Sputter Deposition Technology: Principles, Technology and application, Noyes Publications, (Park Ridge NJ 1992), p.228.

15. N. Yokoyama, K. Hinode, and Y. Homma, J. Electrochem. Soc., 136 (1989), p.882.

16. S. Motojima, K. Baba, K. Kitatani, Y. Takahashi, and K. Sugiyama, J. Cryst. Growth, 32 (1976), p.141.

17. Naresh C. Saha and Hadand G. Tompkins, J. Appl. Phys. 72 (7)(1992), p.3072-3079

18. D. Chaussende, P.J. Wellmann, and M. Pons, J. Phys. D 40 (2007), p.6150.

19. B.M. Epelbaum, M. Bickermann, S. Nagata, P. Heimann, O. Filip, and A. Winnacker, J. Cryst. Growth 305 (2007), p.317.

20. L. Mercurio, L. Du, J.H. Edgar, and E.A. Kenik, Mater. Res. Soc. Symp. Proc., Pittsburgh, PA (2007), 955

21. Material Safety Data Sheet, Electronic Space Products International

22. D.W. Greenwell, B.L. Markham, F. Rosenberger, J. Crystal Growth 51 (1981), p.413. 
Journal of Materials Science: Materials in Electronics, volume 21, number 1, January 2010, pp 78-87.

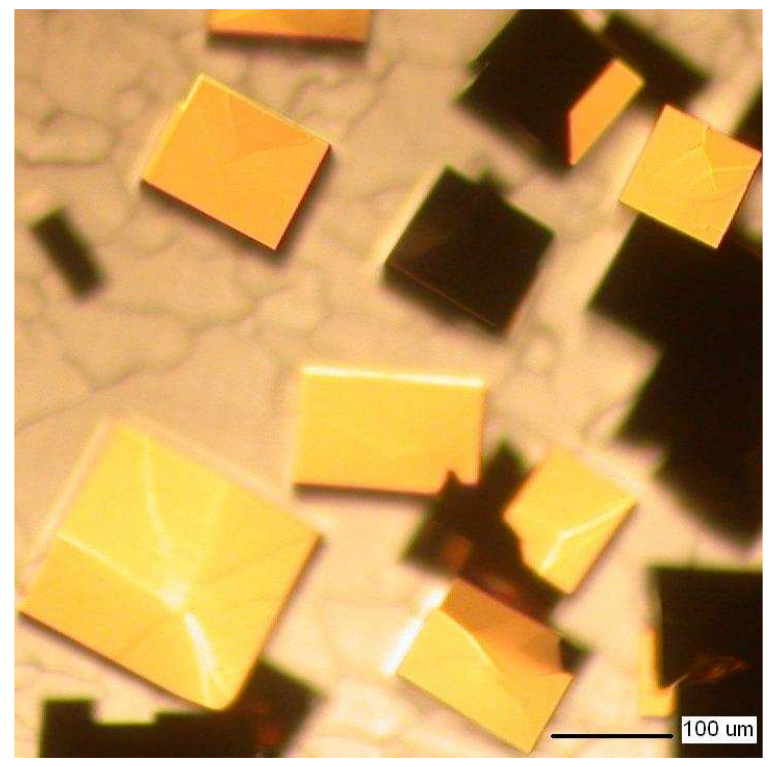

Fig. 1 Optical microscope images of TiN crystals grown on W.

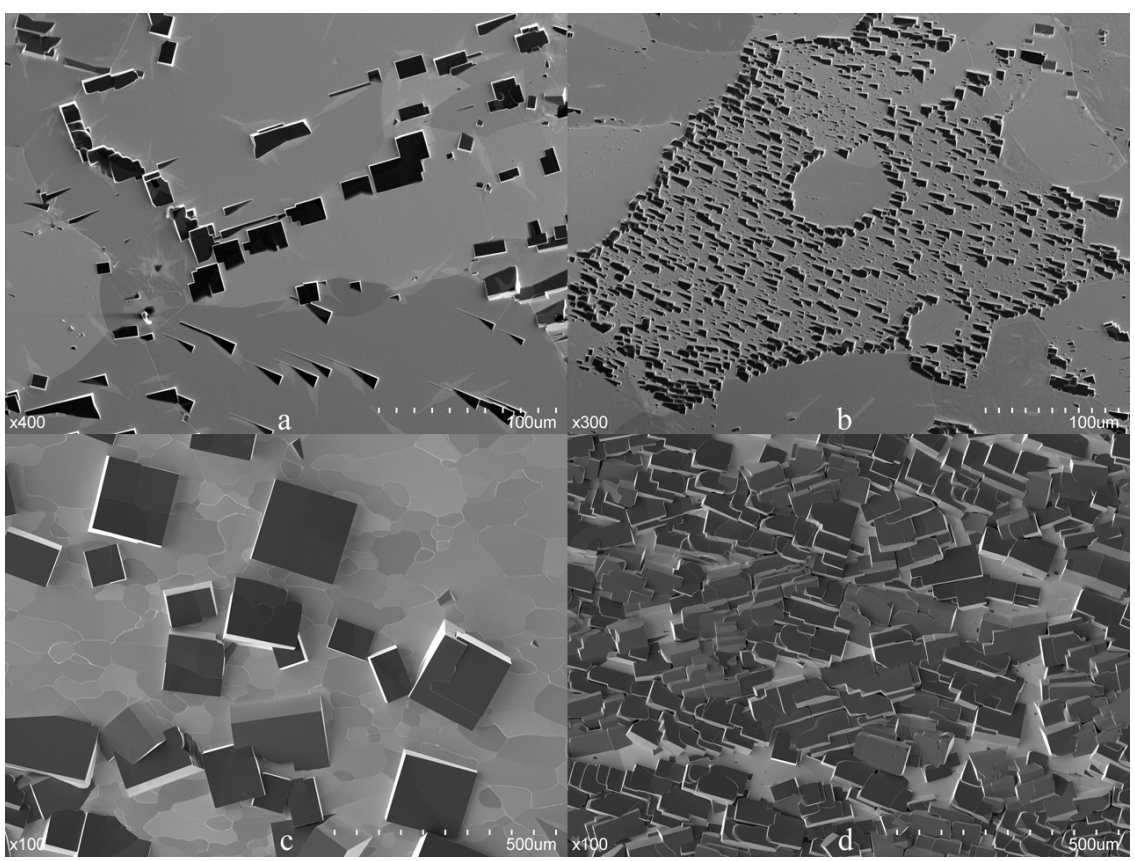

Fig. 2 SEM top view of TiN crystals grown for

30 mins at $2100{ }^{\circ} \mathrm{C}, 1.25 \mathrm{~atm}(\mathrm{a}), 2000{ }^{\circ} \mathrm{C}, 0.8 \mathrm{~atm}(\mathrm{~b}), 15 \mathrm{hrs}$ at $2000{ }^{\circ} \mathrm{C}, 0.2 \mathrm{~atm}(\mathrm{c}, \mathrm{d})$ After 30 mins growth, some preferential crystal nucleation takes place along the tungsten grain boundaries (a), the crystals within the same tungsten grain have similar shapes and orientions (b). After 15 hours growth, the top surfaces of single TiN crystals are square or rectangular (c), grains merged together display more irregular shapes (d). 
Journal of Materials Science: Materials in Electronics, volume 21, number 1, January 2010, pp 78-87.

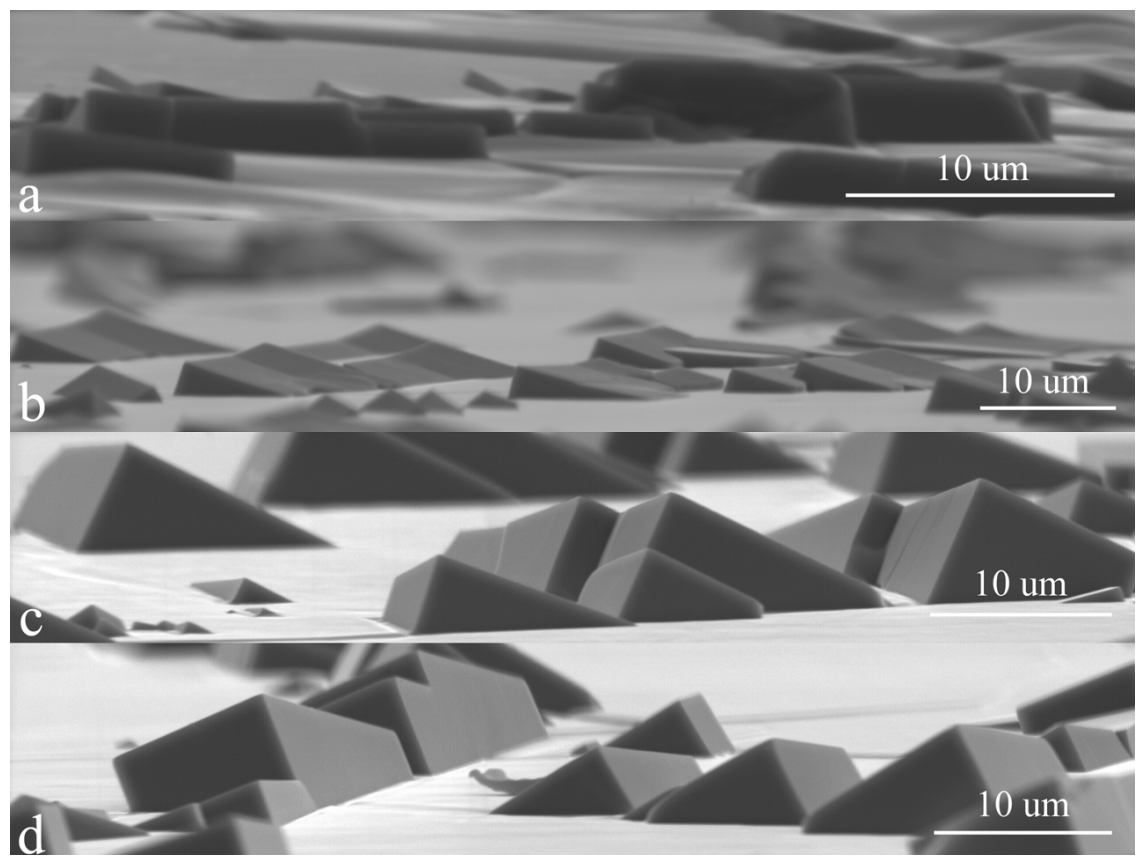

Fig. 3 SEM side-view images of TiN crystals grown for 30 mins at $2000{ }^{\circ} \mathrm{C}, 1.25 \mathrm{~atm}$ (a and b) and $2100{ }^{\circ} \mathrm{C}, 1.25 \mathrm{~atm}(\mathrm{c}$ and d).

Crystals with square or rectangular surfaces were orthorhombic (a) or wedge (b) shaped, and crystals with triangular surfaces were titled wedges (c) or truncated cubes (d).

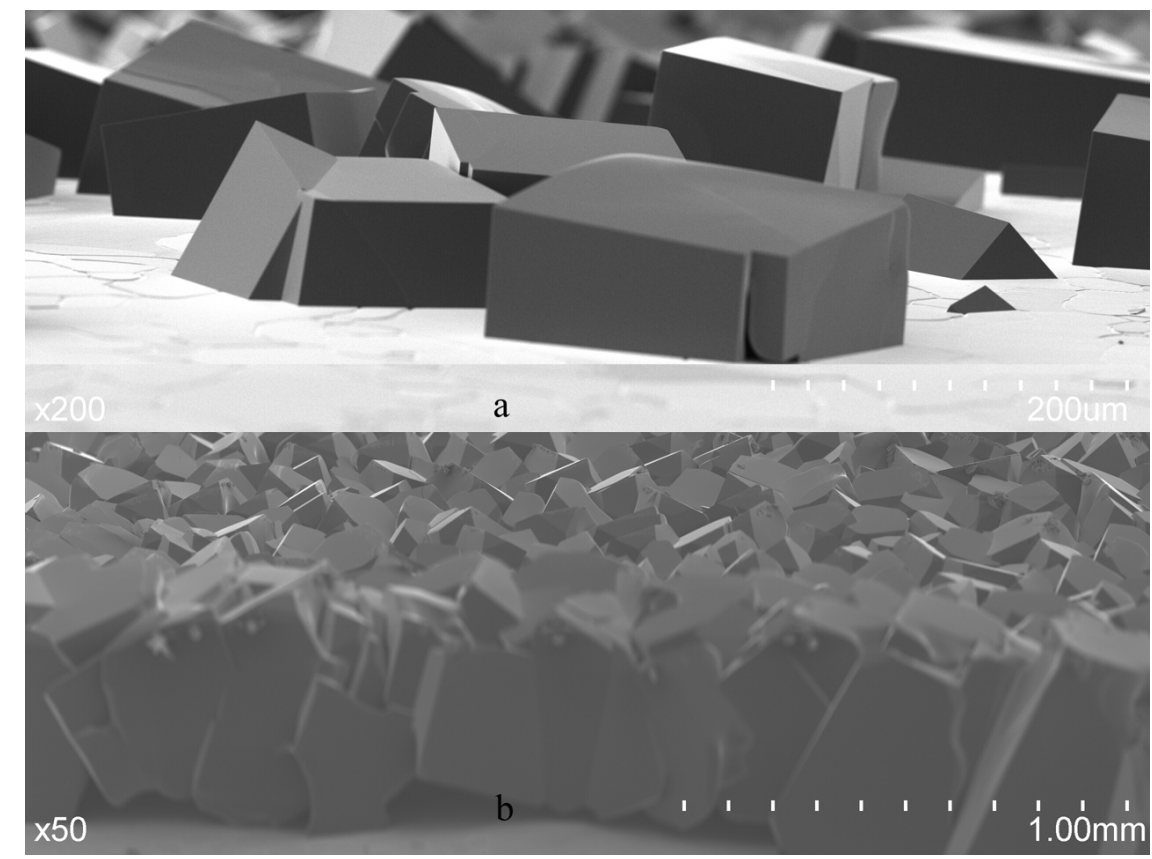

Fig. 4 SEM side-view images of TiN crystals grown for $15 \mathrm{hrs}$ at (a) $0.2 \mathrm{~atm}, 2000{ }^{\circ} \mathrm{C}$, where most individual crystals maintain an orthorhombic shape, and (b) $2100{ }^{\circ} \mathrm{C}$, where $\mathrm{TiN}$ crystals have merged to form a continuous film, the TiN separates from the tungsten substrate in places (shown by arrow). 
Journal of Materials Science: Materials in Electronics, volume 21, number 1, January 2010, pp 78-87.

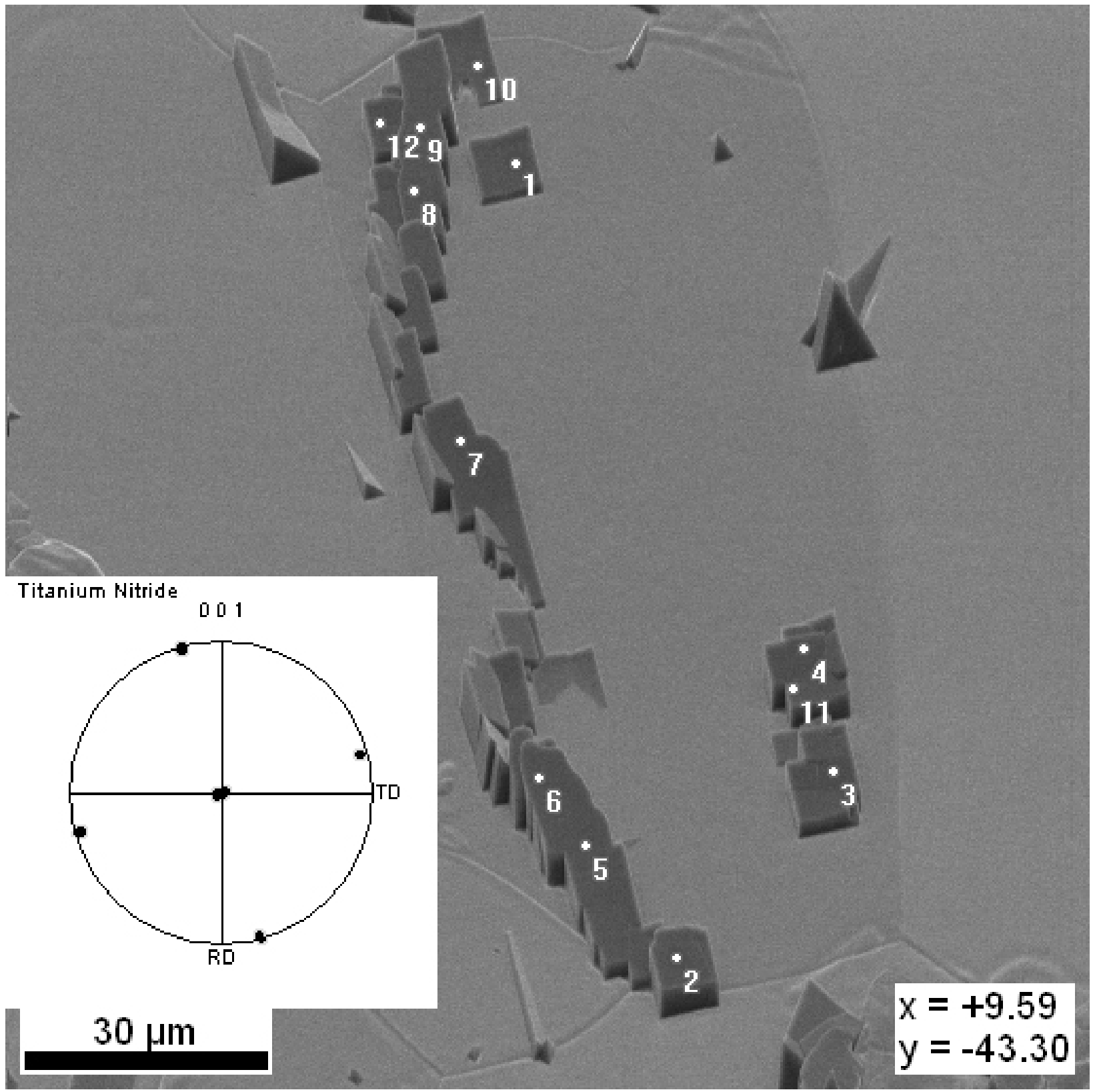

Fig. 5a SEM image and pole figure of selected TiN crystals for crystals shown in sample 1. All TiN grains were oriented with [001] normal to the substrate (center of the pole figure) 
Journal of Materials Science: Materials in Electronics, volume 21, number 1, January 2010, pp 78-87.

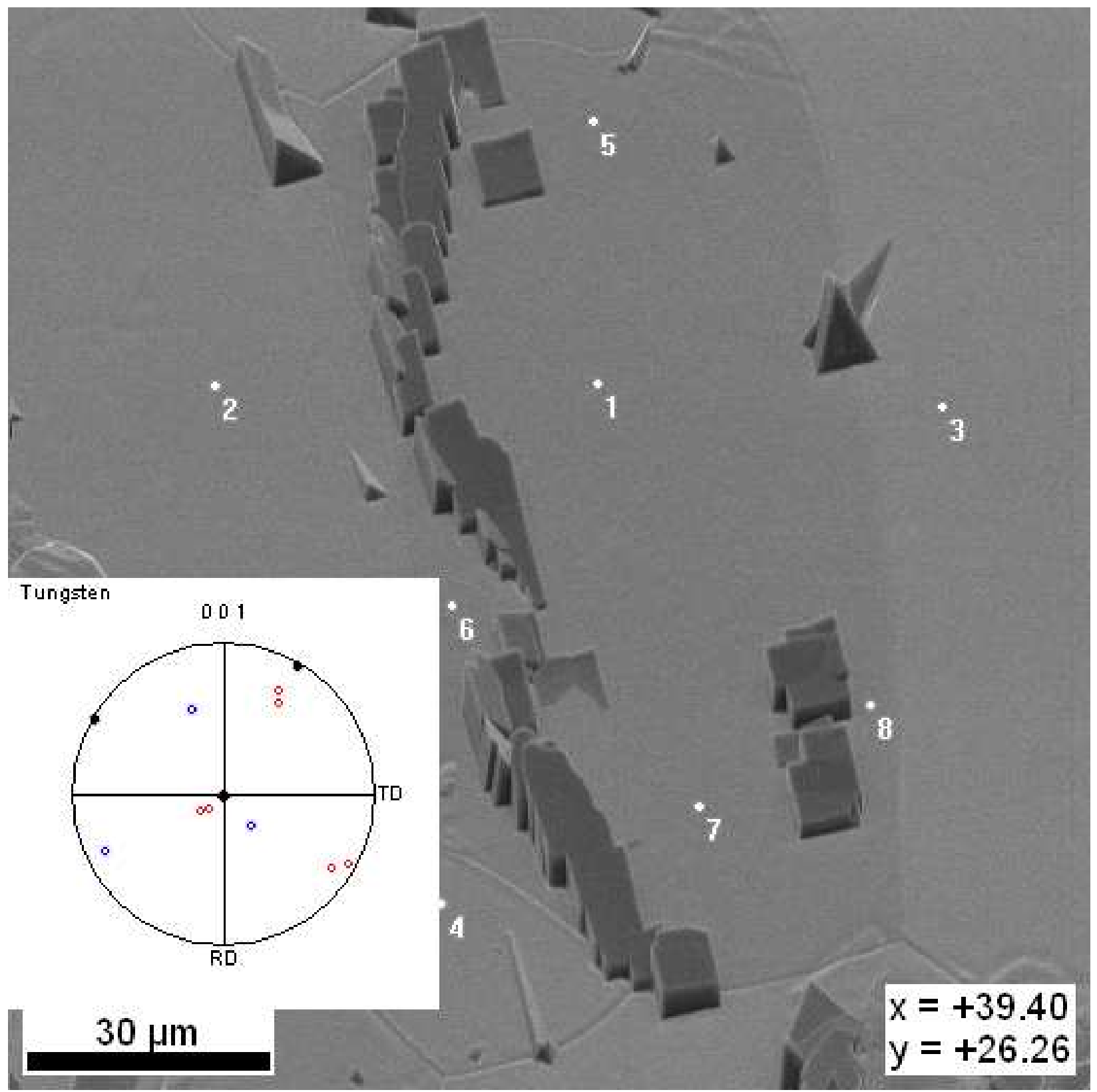

Fig. 5b SEM images and pole figure of tungsten grains for selected areas in sample 1. Tungsten grain (points 1, 5, 6, 7, 8) underlying the selected TiN crystals in Fig. 5a were oriented with (001) surface normal (solid symbols in the pole figure); Adjacent tungsten grains (points $2,3,4)$ showed orientations with (001) offset from the substrate normal (hollow symbols in the pole figure) 
Journal of Materials Science: Materials in Electronics, volume 21, number 1, January 2010, pp 78-87.

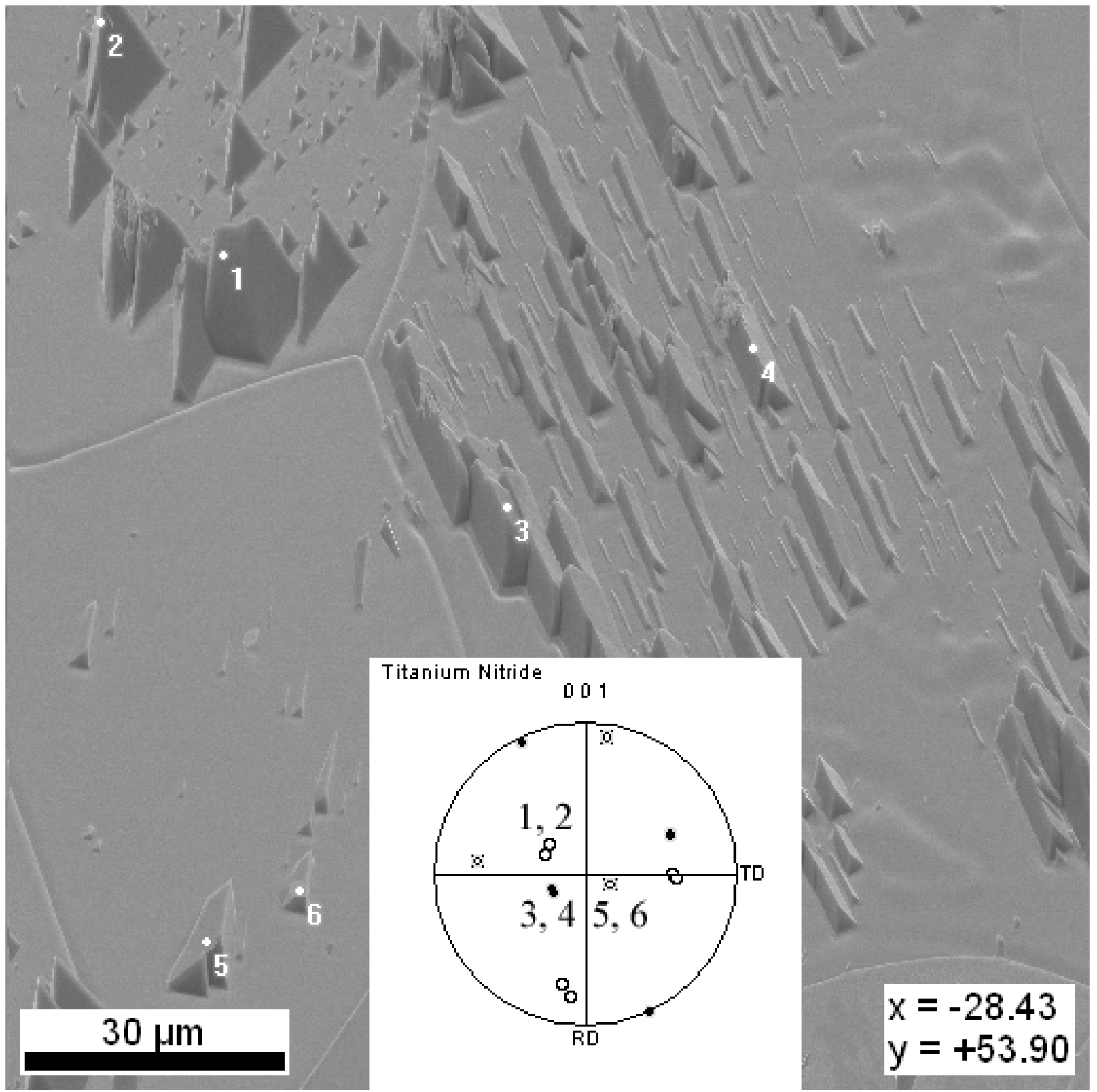

Fig. 5c SEM images and pole figure of TiN crystal for areas designated in sample 2.

TiN crystals grown on same tungsten grain ( 1 and 2,3 and 4, 5 and 6 ) were oriented in the same way (one symbol pattern in the pole figure represents one orientation, symbols for different TiN grains with the same orientation overlap). 
Journal of Materials Science: Materials in Electronics, volume 21, number 1, January 2010, pp 78-87.

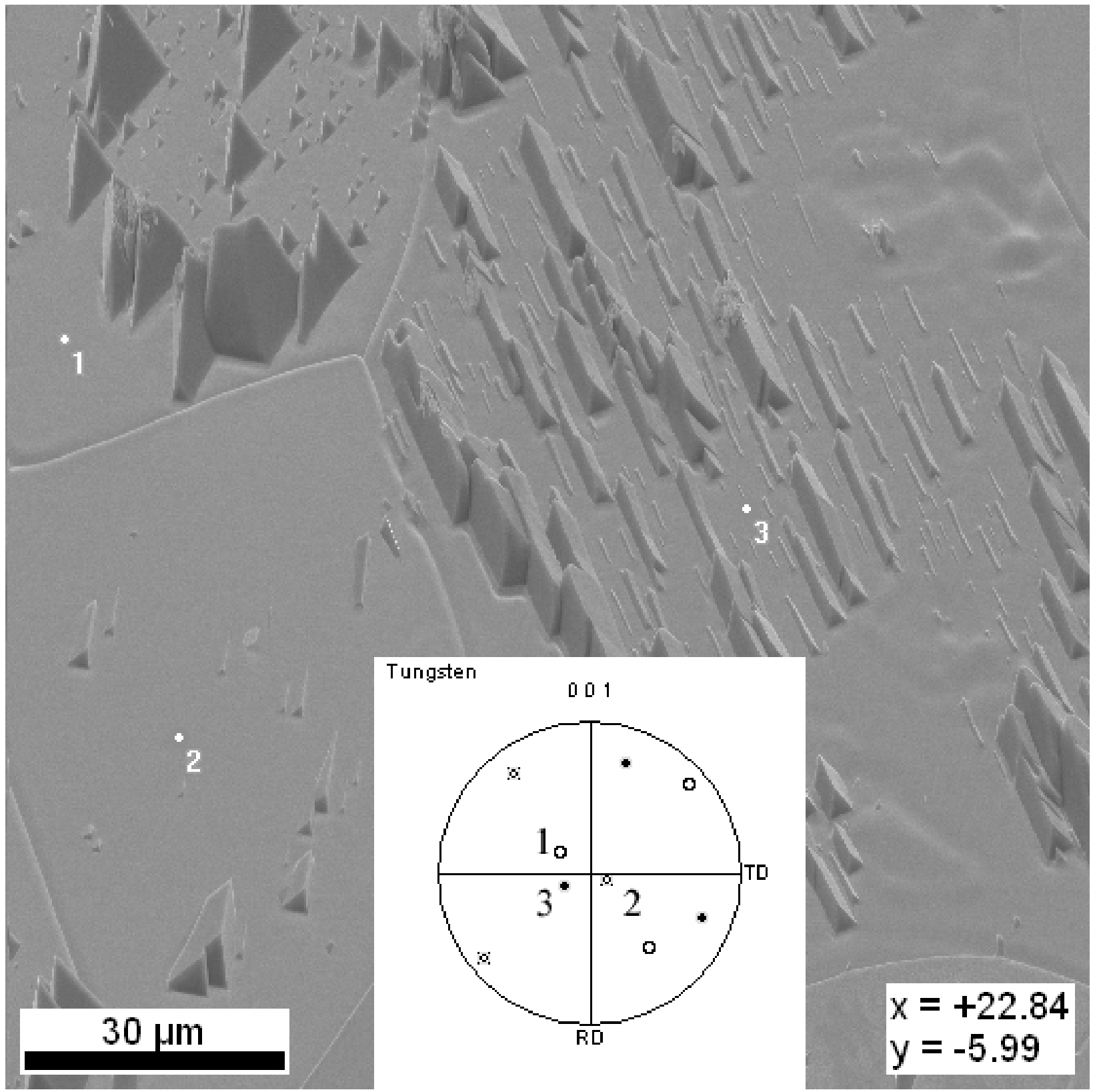

Fig. 5d SEM images and pole figure of the tungsten grains for areas designated in sample 2. The adjacent tungsten grains underling the TiN crystals (1, 2 and 3) were oriented with (001) offset from the substrate normal ; all selected TiN were oriented with (001) parallel to the underling tungsten (001) with a $4^{\circ}$ angle between TiN (100) and W (100). 
Journal of Materials Science: Materials in Electronics, volume 21, number 1, January 2010, pp 78-87.

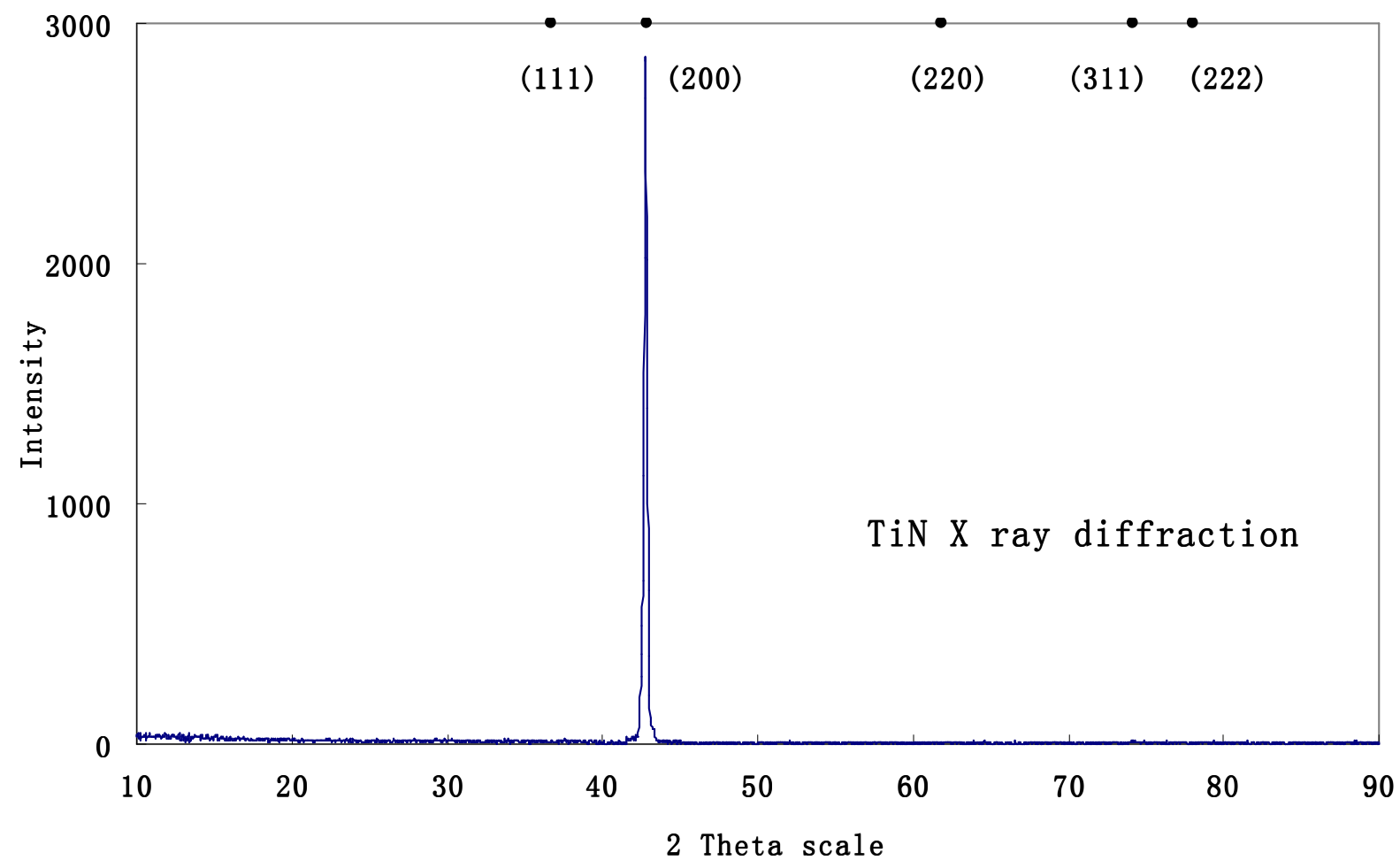

Fig. 6 XRD analysis on thick TiN layer $\left(6 \mathrm{~mm}, 2000{ }^{\circ} \mathrm{C}, 0.2 \mathrm{~atm}\right)$ with strong $(200)$ texture 
Journal of Materials Science: Materials in Electronics, volume 21, number 1, January 2010, pp 78-87.

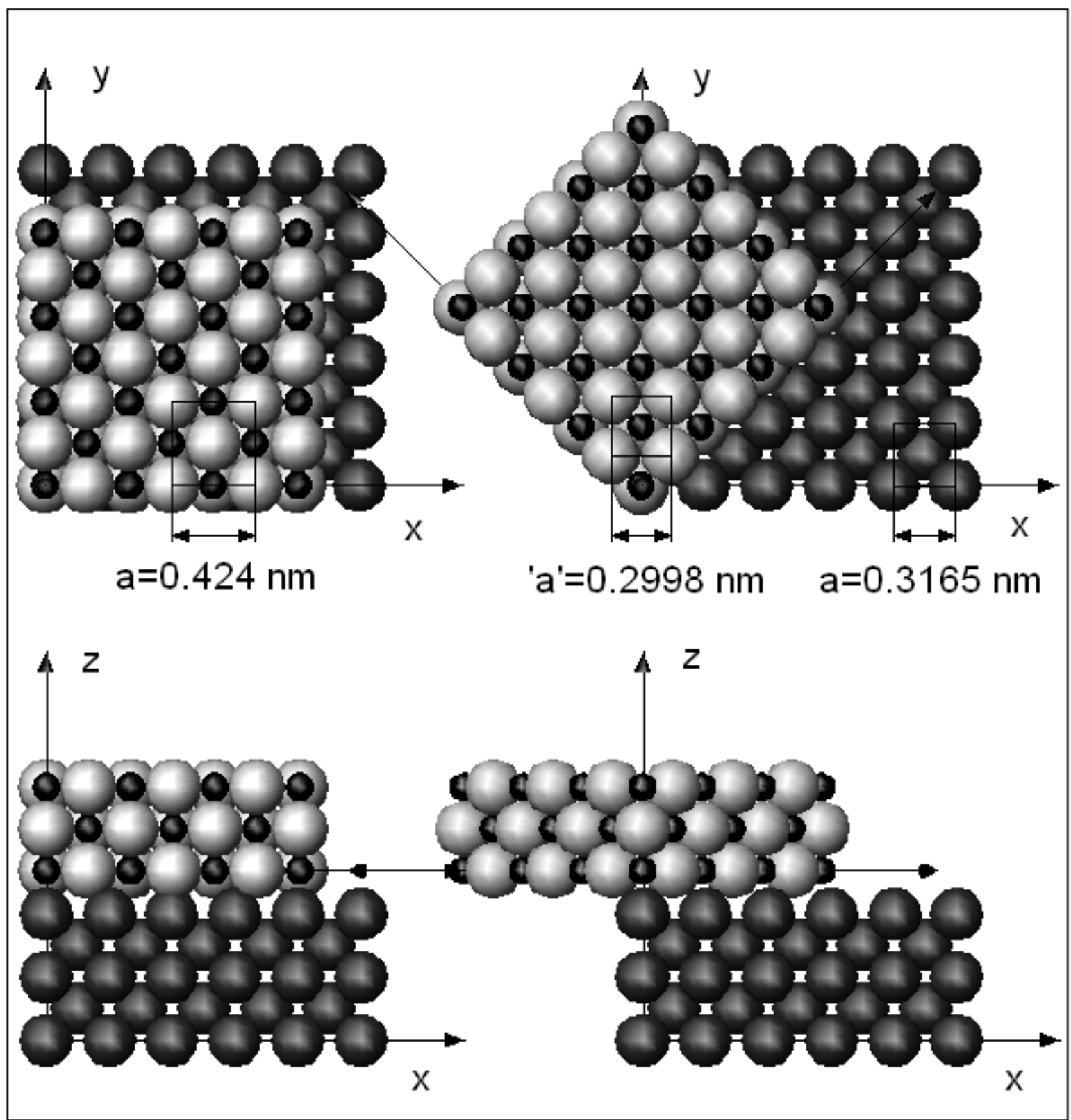

Fig. 7 A schematic representation of TiN (100) crystals grown on (100) tungsten. Large dark gray spheres are tungsten, small black spheres and white spheres are Ti and $\mathbf{N}$, respectively.

Top: top view, bottom: side view, left: $\mathrm{TiN}[100] / / \mathrm{W}[100]$, right: $\mathrm{TiN}[100] \cap W[100]=45^{\circ}$ The orientation of $\mathrm{TiN}(001) \| \mathrm{W}(001)$ with $45^{\circ}$ angle of their in-plane [100] can minimize the lattice constant mismatch. 
Journal of Materials Science: Materials in Electronics, volume 21, number 1, January 2010, pp 78-87.

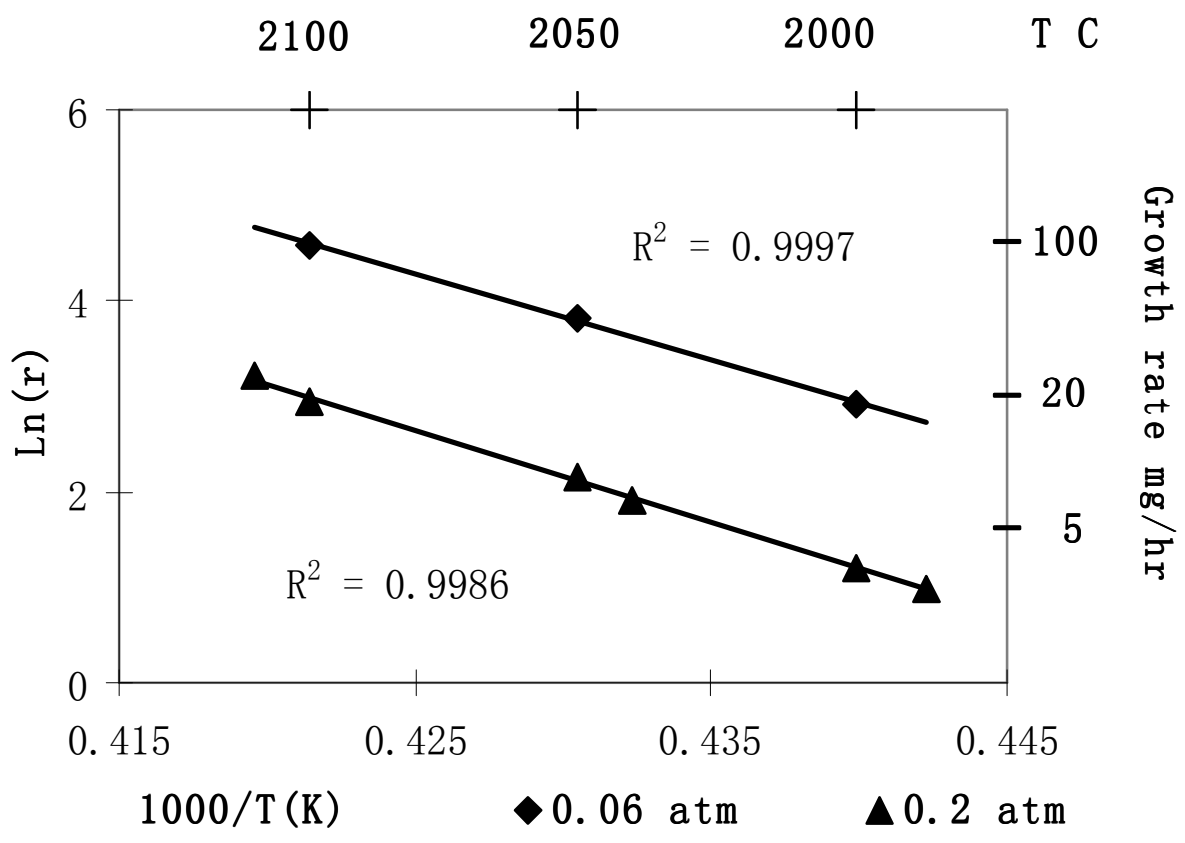

Fig. 8 The variation of the logarithmic growth rate on reciprocal growth temperature at constant growth pressure.

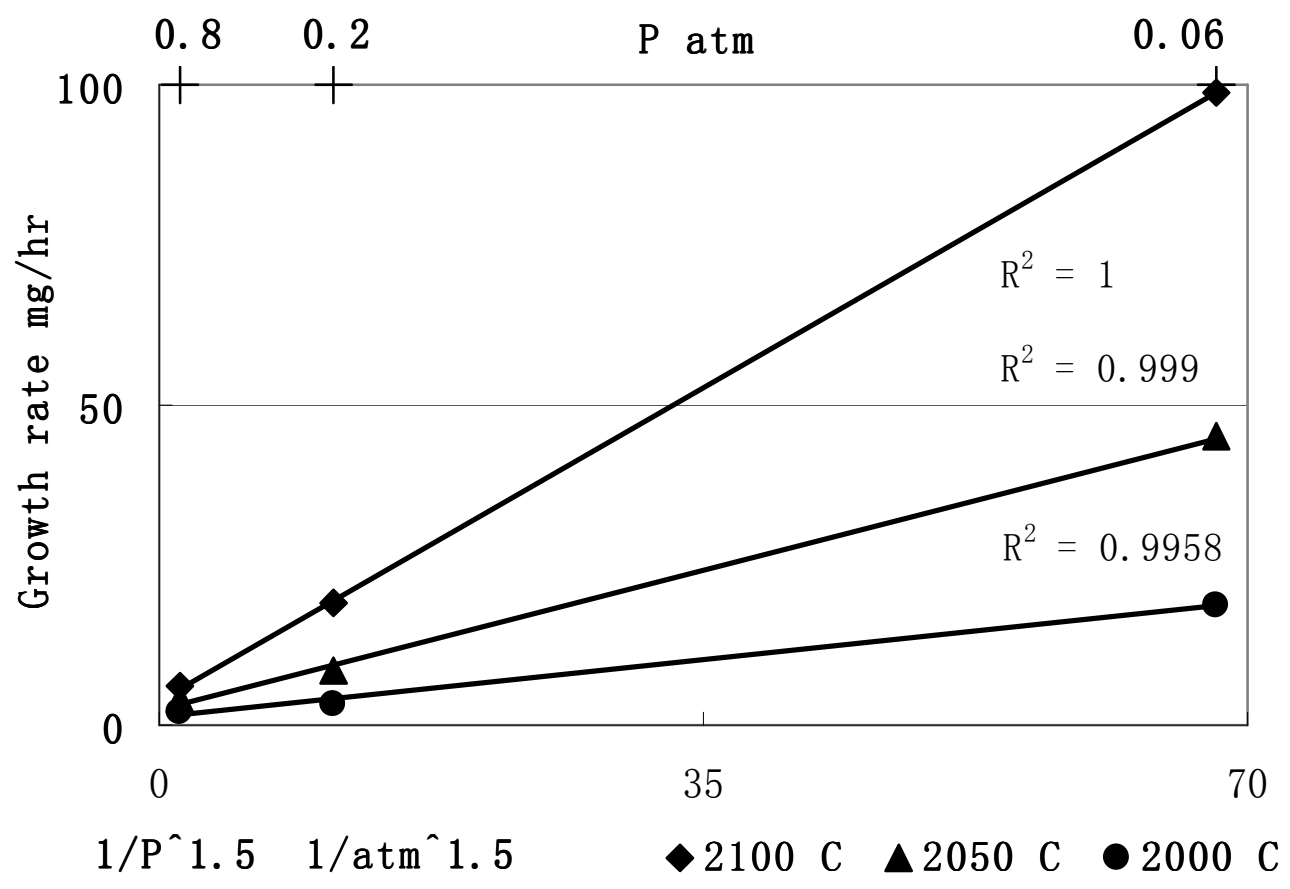

Fig. 9 The growth rate variation with reciprocal pressure at constant growth temperature. 
Journal of Materials Science: Materials in Electronics, volume 21, number 1, January 2010, pp 78-87.

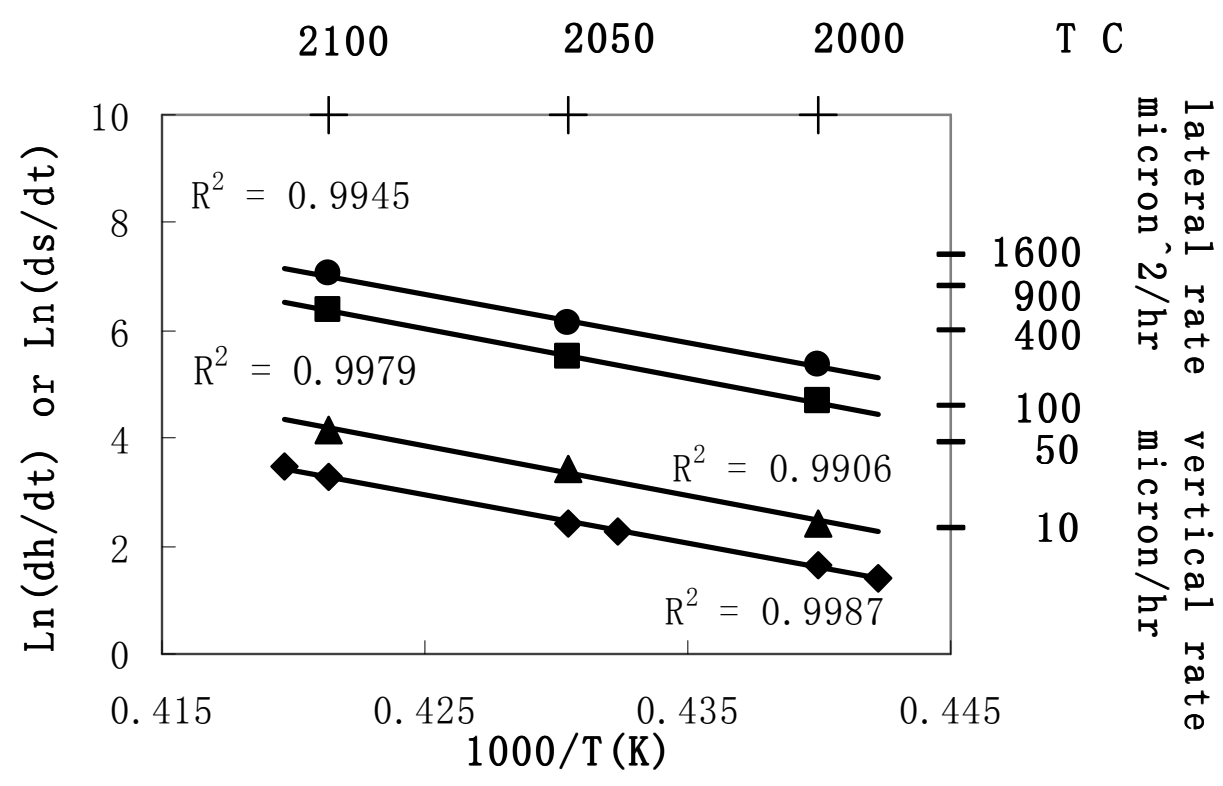

$\diamond 15$ hrs $\Delta 12$ hrs 30 mins $0.8 \mathrm{~atm} \square 30 \mathrm{mins} 1.25 \mathrm{~atm}$

Fig. 10 Logarithmic lateral growth rate vs reciprocal temperature for two 30 mins growths and logarithmic vertical rate vs reciprocal temperature for $12 \mathrm{hrs}$ and $15 \mathrm{hrs}$ growth 